\title{
LOS PAISAJES HORTÍCOLAS EN EL VÉNETO: EVOLUCIÓN Y REPERCUSIONES SOCIO-ESPACIALES ${ }^{1}$
}

\author{
María Hernández Hernández
}

\section{RESUMEN}

Los cultivos hortícolas de la región del Véneto ocupan una superficie reducida si se comparan con la de los cereales o las plantas industriales. Aprovechamientos que, no obstante, van a tener notables repercusiones socio-espaciales en las áreas donde éstos aparecen y que podemos sintetizar en el incremento de las rentas percibidas por los agricultores, la génesis de paisajes intensivos a modo de «islas» en un entorno extensivo, la adopción de nuevas técnicas, etc. Cultivos que no obstante, presentan ciertas disfuncionalidades entre las que sobresalen las carencias desde el punto de vista de su comercialización, a pesar de ciertas iniciativas que se han creado en los últimos años, entre las que destacan las llevadas a cabo por las cooperativas «Verde Europa» (Verona) o la AOMT. S. Bovo (Treviso).

Palabras clave: Véneto, aprovechamientos hortícolas, agricultura protegida, invernaderos, comercialización.

\begin{abstract}
The horticultural cultures on Veneto region have a reduced area if we compare them with surfaces of cereal and industrial cultures. These, nevertheless, have remarkable social and spatial repercussions on areas where this use appears. Repercussions which we can be reduced to the increase of farmer rents, the appearance of intensive landscapes, and diffusion of new techniques. However, these cultures have some deficiencies on subject as dealing in spite of initiatives started by cooperatives as «Green Europe (Verona)» or AOMT. S. Bovo (Treviso).
\end{abstract}

Key words: Veneto, horticultural cultures, winter quarters, dealing.

1 Investigación realizada gracias a una beca posdoctoral del Ministerio de Asuntos Exteriores italiano y que se desarrolló del 01-01-1998 al 31-08-1998, en el departamento de Geografía de la Università degli Studi di Padova, bajo la dirección del catedrático Dario Croce. 


\section{Introducción}

Los terrazgos agrícolas de la región del Véneto presentan notables limitaciones físicas debido a su intrincada orografía (sectores montañosos ${ }^{2}$ ) y a los problemas de avenamiento en las áreas litorales y en la desembocadura de los cursos fluviales como el $\mathrm{Po}^{3}$ ), lo que obligó a una intensa labor de bonificación para su puesta en cultivo. Territorios que se contraponen a la llanura padana, donde la posibilidad de irrigación, la fertilidad de los suelos y el fácil acceso al mercado la convirtieron en el espacio con mayor vocación agrícola (lámina 1).

La importancia de esta región, desde el punto de vista agrícola, no reside únicamente en el valor de su producción ${ }^{4}$, sino en el hecho de que nos encontramos ante un modelo «nuevo», no porque se haya superado el sistema tradicional, sino porque partiendo de éste ha desarrollado características peculiares. Estando éstas determinadas por la dificultad de trazar un límite claro entre lo que pertenece al sector primario y lo que no, e incluso más difícil resulta discernir entre asentamiento urbano y rural. Afirmaciones estas últimas que condujeron a que diversos autores acuñaran el concepto de «Terza Italia ${ }^{5} »$. Entendiendo por éste, aquellas regiones que se caracterizan por una economía «difussa e policentrica ${ }^{6}$ » y en las que las actividades primarias tuvieron una notable influencia en la industrialización y, paralelamente, el influjo que esta nueva actividad tuvo sobre los paisajes agrarios ${ }^{7}$.

\subsection{El sector agrario}

Los espacios agrícolas vénetos desde la década de los cincuenta han experimentado una evolución similar a la del resto del país ${ }^{8}$. Tendencia que podemos sintetizar, grosso modo, en la reducción del número de explotaciones, de activos y de superficies cultivadas, el progresivo envejecimiento de los agricultores y la intensificación de los aprovechamientos.

Esta región en el periodo comprendido entre 1960-91 ha conocido un decrecimiento en el número de las explotaciones cifrado en unas 86.981 unidades $^{9}$. Guarismo que ha supues-

2 BERNI, P. y FABBRIS, L. (1983): Montagna e marginalità nel Veneto. Una analisi tipologica delle malghe venete nella prespettiva dell'intervento pubblico, Región Véneto, Venecia.

3 BERTONCIN, M. (1994): Logiche di terra e acqua. El delta del Po, Tesis doctoral inédita. Cortesía de la autora.

4 El Véneto es la tercera región italiana desde el punto de vista de la producción agrícola, tras EmiliaRomaña, y Lombardía, aportando al producto interior bruto regional el 4,16\% del total, es decir, unos 59.070,2 millones de euros (1997). No obstante, la desagregación de la información a nivel provincial proporciona datos de mayor valor geográfico. Diferencias que debemos relacionar con las diferentes condiciones fisicas que caracterizan a cada provincia, los cultivos dominantes y la existencia de canales de comercialización bien organizados tal y como sucede en Verona y Rovigo, donde las actividades agrarias generan unos ingresos de 18.762,8 y 13.900,9 millones de euros, respectivamente frente a Belluno donde éstos se reducen a 0,37 billones como consecuencia del carácter montano de la provincia y el elevado porcentaje de producción para el autoconsumo.

5 MUSCARÀ, C. (1967): La Geografia dello sviluppo, Comunità, Milán; BAGNASCO, A (1975): Tre Italie: la problematica territoriale dello sviluppo italiano, Il Mulino, Bolonia.

6 RIZZO, G. (1989): «Veneto. Alla ricerca di nuove strategie», en LANDINI, P. e SALVARTORI, F. (a cura di): I sistemi locali delle regioni italiani (1970-1985), Roma, Soc. Geogr. Ital, pp. 119-166.

7 GIACOMINI, C. (1986): «Stato attuale della produzione e dell'organizzazione agricola della Regione Veneto», Atti del Convegno Sistema agro-alimentare. Il caso Veneto, Cassa di Risparmio di Verona, Vicenza e Belluno, pp. 111-136; ANASTASIA, B. (1996): Evoluzione di l'economia regionale: Il Nordest dopo il suceso, Nuove dimenzione, Ediciclo, Portogruaro.

8 FABIANI, G. (1986): L'agricoltura italiana tra sviluppo e crisi (1945-85), Il Mulino, Bolonia.

9 El número de explotaciones y la superficie cultivada de la región del Véneto, según el Censo Agrario de 1991, ascendía a 236.783 explotaciones y $943.777,03$ hectáreas. 


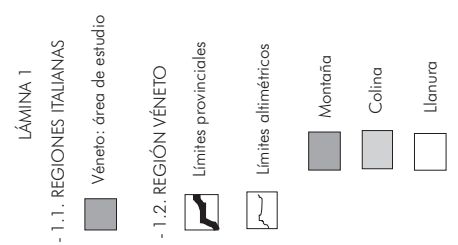

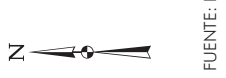

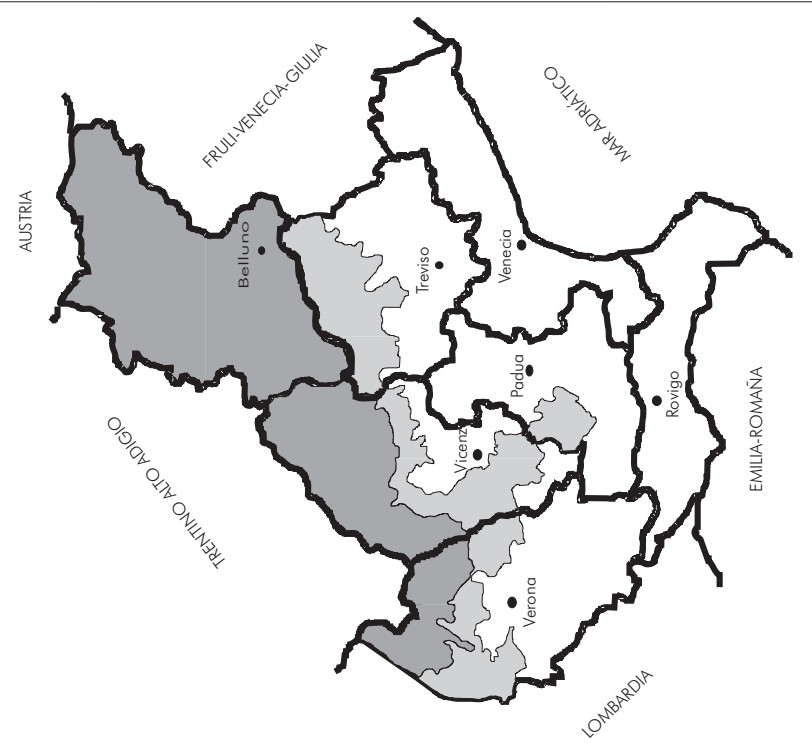

$\stackrel{1}{-}$

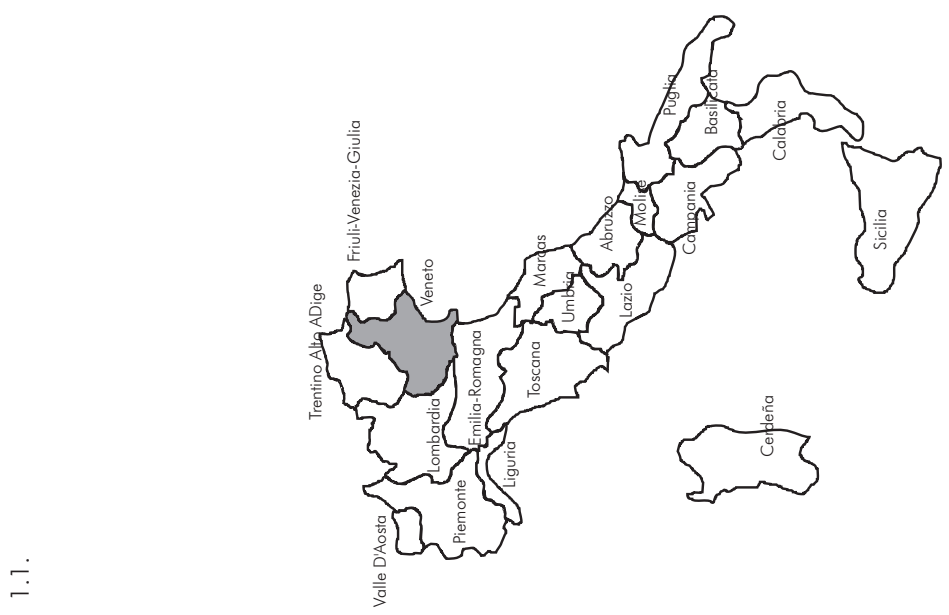


to el abandono de 148.385 hectáreas, de las cuales 58.689 corresponden a la superficie agraria cultivada. Tendencia que se ha acentuado al analizar los activos agrarios. En 1951, el sector primario ocupaba al $43 \%$ de la población en edad de trabajar frente al 5,82\% de 1991. Descenso que debemos relacionar con la difusa industrialización que caracteriza a este ámbito y que se tradujo en una primera etapa en el incremento de los activos secundarios y, posteriormente, una terciarización de la sociedad, ocupando estos sectores, según el último censo, al 43,9 y 50,3\%de los asalariados, respectivamente.

La evolución descrita no sólo ha determinado una drástica reducción de la mano de obra con la consiguiente dificultad a la hora de encontrar trabajadores, sino también su progresivo envejecimiento al no producirse la incorporación de agricultores jóvenes, lo que a medio e incluso a breve término puede generar problemas de continuidad en muchas explotaciones, dados los elevados porcentajes de trabajadores con más de 45 años $^{10}$.

Otra característica del agro véneto, consecuencia de la difusa industrialización, es el elevado porcentaje de agricultura a tiempo parcial, salvo en la provincia de Belluno ${ }^{11}$. Dominio de las actividades secundarias que determina que las rentas agrarias aunque sean elevadas, no puedan competir con los ingresos generados por las manufacturas. Además, tal y como indicaba el técnico de la denominación de origen del espárrago de Bassano ${ }^{12}$, los hijos de los actuales cultivadores prefieren realizar alguna hora extra en la industria local que cultivar la tierra. Descendientes que cuando acceden a su propiedad optan, generalmente, por su extensificación dados los menores atenciones que el maíz o la soja requieren.

Los cultivos herbáceos y, concretamente los cereales y las plantas industriales, son, desde el punto de vista de los aprovechamientos agrícolas, dominantes al ocupar el 45,02\% de la superficie cultivada, frente al 9,63\% de los leñosos. Dedicándose el resto del terrazgo $(14,70$ y $18,15 \%)$ a pastos y a bosques, respectivamente. Porcentajes que, no obstante, presentan notables variaciones según el sector altimétrico en el que nos hallemos: en la baja llanura y en el área deltaica, el maíz y la soja alcanzan valores en torno al $80 \%$ en la provincia de Rovigo y del $60 \%$ en las de Verona y Vicenza. Aprovechamientos arbóreos que serán dominantes, en cambio, en el área colinar, donde dan lugar a la aparición de cultivos especializados (viñedo, frutales y, en menor medida el olivo en los alrededores del lago de Garda) (lámina 1). Mención especial revisten los cultivos hortícolas que, si bien ocupan una superficie reducida, generan notables repercusiones socio-espaciales que se manifestarán en la formación de «islas» en un entorno dominado por los usos extensivos.

Los aprovechamientos citados han registrado una evolución (cuadro 1) desde los años 70 que, grosso modo, podemos sintetizar en el progresivo incremento de las superficies ocupadas por los herbáceos y la reducción de los leñosos excepto en la provincia de Verona, como consecuencia de los problemas de comercialización y encarecimiento de costes que éstos conllevan y que se han acentuado desde finales de los ochenta frente a los menores cuidados y las subvenciones recibidas por los primeros, que los convierten en «cultivos refugio» muy adecuados para la práctica de la agricultura a tiempo parcial.

10 Porcentajes que oscilan, según el Censo de Población, entre el 70,83\% de Rovigo y el 56,21\% de Belluno.

11 En la provincia de Belluno la agricultura a tiempo parcial ocupa únicamente el 1,41\% de las explotaciones agrarias como consecuencia del carácter marginal que tradicionalmente ha tenido esta actividad, frente a porcentajes en torno al $33,64 \%$ de las provincias de Venecia y Padua.

12 Bassano del Grappa posee una denominación de origen para el espárrago blanco. Éste en la campaña de 1998 ha alcanzado una cotización de 413,16 euros/kg; obteniéndose unas rentas netas que oscilan entre las 6,71 euros/kg y los $1.549,37$ euros para las parcelas que dedican entre 1.000 y $3.000 \mathrm{~m}^{2}$. Productores que complementan esta producción con otros cultivos hortícolas o la ganadería. No obstante, el 75\% de los 185 socios agrupados bajo esta denominación son agricultores a tiempo parcial. 


\section{Cuadro 1}

EVOLUCIÓN DE LOS APROVECHAMIENTOS AGRARIOS: 1971-1991

\begin{tabular}{|c|c|c|c|c|c|c|c|c|c|}
\hline & \multirow[t]{3}{*}{ sup.total(ha) } & \multirow{2}{*}{\multicolumn{2}{|c|}{ SAU (\%) }} & \multicolumn{4}{|c|}{ herbáceos $(\%)^{*}$} & \multirow{2}{*}{\multicolumn{2}{|c|}{ leñosos $(\%)^{*}$}} \\
\hline & & & & & & \multicolumn{2}{|c|}{ hortalizas $^{\mathrm{a}}$} & & \\
\hline & & 1971 & 1991 & 1971 & 1991 & 1971 & 1991 & 1971 & 1991 \\
\hline Padua & 163584,03 & 88,22 & 85,89 & 79,48 & 84,52 & 1,06 & 2,59 & 14,01 & 10,34 \\
\hline Rovigo & 136834,73 & 87,98 & 87,36 & 89,53 & 95,48 & 3,81 & 4,79 & 7,91 & 4,31 \\
\hline Treviso & 184480,78 & 79,76 & 77,32 & 57,60 & 63,51 & 0,63 & 0,92 & 21,19 & 19,73 \\
\hline Venecia & 155491,84 & 93,78 & 79,06 & 82,77 & 90,26 & 2,10 & 2,95 & 14,82 & 8,27 \\
\hline Verona & 219212,66 & 90,34 & 82,55 & 53,02 & 54,39 & 4,62 & 4,55 & 24,44 & 26,04 \\
\hline Vicenza & 196809,48 & 73,02 & 60,71 & 45,06 & 46,15 & 0,91 & 1,32 & 9,71 & 9,23 \\
\hline
\end{tabular}

*: Porcentajes realizados sobre la superficie agraria útil; ${ }^{\text {a }}$ : porcentajes sobre la superficie de herbáceos Fuente: Censos Agrarios de 1971 y 1991. Elaboración propia.

\section{Los cultivos hortícolas en el Véneto}

\subsection{La evolución de la superficie cultivada y de las explotaciones}

La superficie dedicada a cultivos hortícolas ha experimentado un notable incremento desde los años 50, cuando éstos, salvo excepciones, se destinaban al autoabastecimiento (huertos familiares) o al mercado local: de $15.718,15$ hectáreas en $1971^{13}$ se ha pasado a 28.800 hectáreas y una producción de 669.000 toneladas en $1997^{14}$ (cuadro 2). Terrazgos que, grosso modo, se mantienen estables desde inicios de la década de los noventa, observándose, pequeñas reducciones que debemos relacionar con las negativas condiciones climáticas que se han producido en las tres últimos campañas (escasez de precipitaciones en el periodo de crecimiento, lluvias intensas y granizo en los periodos de recolección, etc.) y la adecuación a la demanda del mercado.

Superficie que debemos desglosar entre aquélla ocupada por las técnicas al aire libre (25.751 hectáreas y una producción de 576.705 toneladas) y la protegida (3.440 hectáreas y 92.955 toneladas $^{15}$ ). Localizándose las mayores áreas hortícolas en las provincias de Rovigo, Verona y Venecia con 5.470, 4.487 y 3.225 hectáreas respectivamente frente a valores prácticamente inexistentes en Belluno (40 hectáreas) como consecuencia de su carácter montano (cuadro 1 y 2). Aprovechamientos que a su vez presentan una localización puntual: litoral de la provincia de Venecia, municipios de Lusia, Rosolina y Porto Tolle (provincia de Rovigo), Zevio, Cerea y Bovolone (baja llanura de la provincia de

13 El epígrafe «hortalizas» no se desglosan hasta el Censo Agrario de 1971, lo que dificulta indicar cantidades que no sean más que una mera aproximación.

14 Cifras que presentan significativas variaciones según la fuente consultada. El valor citado ha sido proporcionado por las Cámaras de Comercio vénetas. Éste se elevaría, si atendiéramos a los datos proporcionados por el ISTAT (Instituto de Estadística italiano) hasta 32.368,82 hectáreas y 862.889 toneladas; mientras que se reducirían a 18.031,66 hectáreas si utilizásemos el Censo Agrario de 1991.

15 Guarismos en los que se observan variaciones similares a las citadas en los aprovechamientos hortícolas en general. Éstos oscilarían entre las 1.575 proporcionadas por el censo agrario de 1991, las 2.964,8 del ISTAT y las 3.440 hectáreas de las Cámaras de Comercio. 


\section{Cuadro 2}

LOCALIZACIÓN Y TAMAÑO DE LAS EXPLOTACIONES HORTÍCOLAS

\begin{tabular}{|c|c|c|c|c|c|c|c|c|c|c|c|}
\hline & \multicolumn{2}{|c|}{$-1 \mathrm{ha}$} & \multicolumn{2}{|c|}{$1-5$ ha } & \multicolumn{2}{|c|}{ 5-20 ha } & \multicolumn{2}{|c|}{+20 ha } & \multicolumn{2}{|c|}{ total } \\
\hline & & $n^{0}$ & sup & $\mathrm{n}^{0}$ & sup & $\mathrm{n}^{0}$ & sup & $n^{0}$ & sup & $\mathrm{n}^{0}$ & sup \\
\hline \multirow[t]{3}{*}{$\mathrm{Pd}$} & \multirow{3}{*}{$\begin{array}{l}\text { total } \\
\text { a.libre } \\
\text { ptgdos }\end{array}$} & 589 & 155,2 & 1254 & 941,9 & 781 & 1366,4 & 116 & 602,4 & 2740 & 3066,1 \\
\hline & & 568 & 148,2 & 1213 & 896,6 & 764 & 1039,3 & 112 & 592,3 & 2657 & 2796,6 \\
\hline & & 51 & 7,0 & 151 & 45,3 & 60 & 27,1 & 8 & 10,1 & 270 & 89,5 \\
\hline \multirow[t]{3}{*}{ Ro } & \multirow{3}{*}{$\begin{array}{l}\text { total } \\
\text { a.libre } \\
\text { ptgdos }\end{array}$} & 455 & 157,5 & 928 & 1040,2 & 1536 & 2859,3 & 329 & 1376,5 & 3248 & 5469,5 \\
\hline & & 448 & 152,7 & 916 & 1030,9 & 1522 & 2765,0 & 326 & 1347,5 & 3211 & 5205,1 \\
\hline & & 32 & 4,7 & 196 & 100,3 & 211 & 130,3 & 33 & 28,9 & 417 & 264,3 \\
\hline \multirow[t]{3}{*}{$\mathrm{Tv}$} & \multirow{3}{*}{$\begin{array}{l}\text { total } \\
\text { a.libre } \\
\text { ptgdos }\end{array}$} & 295 & 65,5 & 760 & 403,2 & 280 & 289,3 & 32 & 83,4 & 1367 & 841,6 \\
\hline & & 274 & 60,2 & 726 & 331,4 & 272 & 280,7 & 30 & 77,6 & 1302 & 800,1 \\
\hline & & 36 & 5,2 & 100 & 21,7 & 43 & 8,6 & 4 & 5,8 & 183 & 41,5 \\
\hline \multirow[t]{3}{*}{$\mathrm{Vz}$} & \multirow{3}{*}{$\begin{array}{l}\text { total } \\
\text { a.libre } \\
\text { ptgdos }\end{array}$} & 1125 & 523,9 & 1360 & 1578,3 & 350 & 758,8 & 90 & 412,6 & 2925 & 3444,0 \\
\hline & & 1082 & 478,3 & 1332 & 1426,9 & 344 & 722,1 & 88 & 409,8 & 2846 & 3037,2 \\
\hline & & 169 & 45,6 & 298 & 151,4 & 62 & 36,5 & 8 & 2,85 & 537 & 236,6 \\
\hline \multirow[t]{3}{*}{$\mathrm{Vr}$} & \multirow{3}{*}{$\begin{array}{l}\text { total } \\
\text { a.libre } \\
\text { ptgdos }\end{array}$} & 294 & 87,8 & 960 & 860,1 & 1020 & 1791,6 & 206 & 1744,9 & 2480 & 4484,5 \\
\hline & & 262 & 73,5 & 752 & 566,6 & 819 & 1293,2 & 175 & 1633,8 & 2008 & 3573,3 \\
\hline & & 51 & 14,2 & 364 & 293,5 & 366 & 498,3 & 43 & 105,1 & 824 & 911,2 \\
\hline \multirow[t]{3}{*}{ Vi } & \multirow{3}{*}{$\begin{array}{l}\text { total } \\
\text { a.libre } \\
\text { ptgdos }\end{array}$} & 451 & 77,0 & 610 & 226,1 & 275 & 250,0 & 45 & 172,7 & 1381 & 725,96 \\
\hline & & 438 & 73,0 & 593 & 207,6 & 270 & 240,6 & 44 & 172,7 & 1345 & 694,06 \\
\hline & & 31 & 3,9 & 70 & 18,5 & 20 & 9,3 & 1 & 0,02 & 122 & 31,90 \\
\hline
\end{tabular}

Pd: Padua; Ro: Rovigo; Tv: Treviso; Vz: Venecia; Vr: Verona; Vi: Vicenza. Fuente: Censo Agrario de 1991. Elaboración propia.

Verona), área en torno al municipio de Bassano de Grappa, Rossà y Cassola (provincia de Vicenza) y Motta de Livenza, Oderzo y Preganziol (provincia de Treviso) tal y como señalaremos en epígrafes sucesivos (lámina 2).

El incremento de la superficie hortícola cultivada desde los años 70 ha ido acompañada de una progresiva disminución en el número de explotaciones; situándose en torno a las 5.000 las unidades productivas cuya principal fuente de ingresos son los citados aprovechamientos. Proceso que ha permitido un progresivo incremento de las superficies medias de las explotaciones que han pasado de 0,6 has en 1960 a 2,5 en 1991; observándose, por tanto, la mayor concentración en el intervalo comprendido entre 1 y 5 hectáreas (cuadro 2). Esta estructura de la propiedad queda corroborada por el trabajo de campo en el área de Bibione, Cavallino y Chioggia y las entrevistas realizadas a agricultores socios de la cooperativa Ortolani de Rosolina y la de Lusia (provincia de Rovigo) y la lonja (mercati de produzione) de Bassano del Grappa quienes afirmaron que las unidades productivas especializadas y con régimen de dedicación exclusivo se sitúan en torno a 3,5-4 hectáreas, si alternan el cultivo al aire libre y técnicas de protección y 2-3 hectáreas si poseen invernaderos frente a las 1,5-2 hectáreas de las no especializadas y a tiempo parcial. 


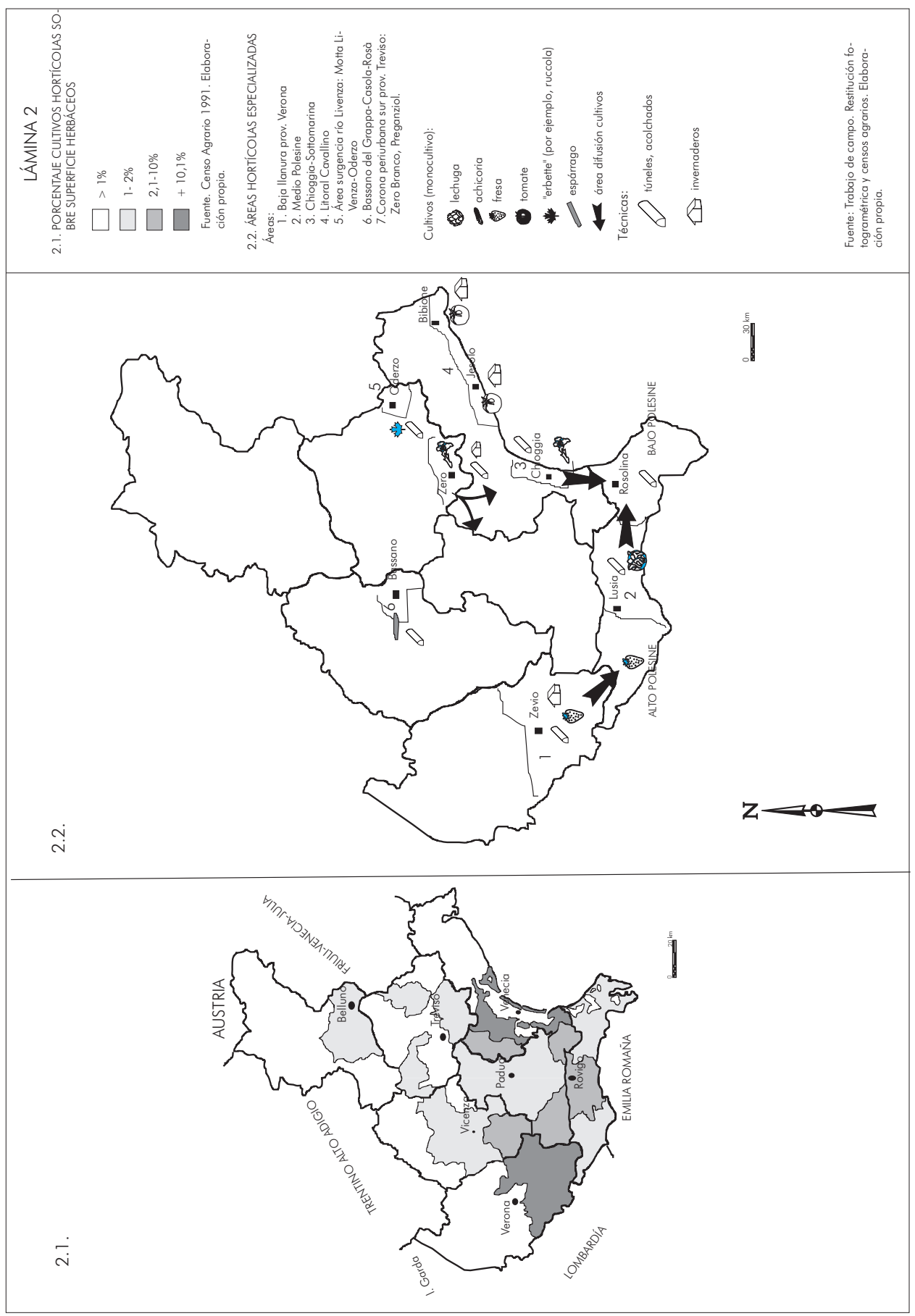


Estas dimensiones condicionan el sistema de gestión: éste es, generalmente, directo y familiar. Régimen determinado, asimismo, por la dificultad de adquirir tierras dada la intensa urbanización del agro véneto que implica su elevado valor ${ }^{16}$, pero también por la falta de mano de obra disponible dada la intensa industrialización que determina que ésta sea escasa y $\operatorname{cara}^{17}$ de ahí que sea extraño el empleo de trabajadores externos a la unidad familiar. A modo de ejemplo, podemos citar dos explotaciones en Lusia, la primera de ellas con una superficie agrícola útil de 3,5 hectáreas donde trabajaban 5 activos todos ellos miembros de la misma familia y la segunda ( 2 hectáreas, la mitad ocupada por invernaderos con calefacción), que empleaba a 6 activos, siendo únicamente uno de ellos un asalariado; aunque el titular de la explotación afirmó que trataba de adaptar la superficie cultivada a la mano de obra familiar.

\subsection{Cultivos dominantes}

El aumento de las superficies hortícolas en una primera etapa y su posterior consolidación queda confirmada al analizar los principales cultivos, en los que distinguiremos entre los que se practican al aire libre y los que adoptan técnicas de protección (cuadro 3). Entre los primeros destacan radicchio $^{18}(27,71 \%)$, patatas $(13,69 \%)$, tomates $(6,58 \%)$, judías $(6,10 \%)$ y coles $(5,60)$ frente a fresas $(32,65 \%)$, tomates $(20,13 \%)$ y melones $(20,52 \%)$ en los segundos. Aprovechamientos que presentan una amplia difusión en el agro véneto, pero junto a ellos debemos citar aquéllos que, aunque su área total es reducida, se caracterizan por una notable concentración espacial lo que los dota de una notable relevancia económica para la zona donde se localizan como sucede, por ejemplo, con el ajo, la lechuga y la zanahoria en la provincia de Rovigo (bajo Polesine) al concentrarse en ella el $87 \%$ y el $50 \%$ de estas cosechas, las fresas en la baja llanura de Verona (90\% de la producción véneta) o las plantas para ensalada (erbette) entre las que destaca la rúcola o la albahaca en la zona de las surgencias del río Livenza. Llegando a constituirse en monocultivos tal y como se observa en el litoral de Chioggia-Sottomarina (achicoria, variedad de Chioggia). Monoespecialización que ha generado aspectos positivos como es la creación de canales de comercialización basados en un único cultivo y orientado al abastecimiento del mercado interior y, en menor medida, exterior, pero también problemas de viabilidad económica relacionados con la dependencia que ésta impone.

Terrazgos que han experimentado pequeñas variaciones (compárese las superficies ocupadas en 1994 y 1997, cuadro 3) que debemos relacionar, entre otras razones, con la adecuación a la demanda del mercado o la búsqueda de cultivos más rentables. Entre los que han incrementado su superficie merece citarse el tomate, tanto al aire libre como bajo plástico, tal y como confirma la restitución fotogramétrica y el trabajo de campo realizado en las pedanías de Cavallino y Punta Sabbioni (Venecia) donde ésta alcanzando el rango de monocultivo. Expansión que se vincula a la existencia de contratos entre productores e industrias transformadoras, bien próximas como las del municipio de San Donà di Piave o distantes como las que tienen su sede en las provincias de Verona o en Ferrara, que aseguran unos precios mínimos a los cultivadores.

16 El precio de una hectárea de terrazgo agrícola oscila entre dos y cuatro millones de pesetas la hectárea.

17 Los salarios medios pagados se situaban en torno a los 7,74 y 10,32 euros/hora. Atribuyéndose a la mano de obra entre el 72 y el $83 \%$ del coste total de los gastos de la explotación.

18 El radicchio es un vegetal de la familia de las achicorias, de ahí que se emplee esta término castellano, aunque debemos indicar que ninguna de las variedades cultivadas en el Véneto se comercializa en España. 
Cuadro 3

EVOLUCIÓN DE LOS PRINCIPALES CULTIVOS HORTÍCOLAS (1994-97)

\begin{tabular}{|c|c|c|c|c|c|c|c|c|}
\hline \multirow{3}{*}{ Cultivos } & \multicolumn{4}{|c|}{1994} & \multicolumn{4}{|c|}{1997} \\
\hline & \multicolumn{2}{|c|}{ ptgdos } & \multicolumn{2}{|c|}{ a.libre } & \multicolumn{2}{|c|}{ ptgdos } & \multicolumn{2}{|c|}{ a.libre } \\
\hline & sup & prod & sup & prod & sup & prod & sup & prod \\
\hline achicoria & 30,8 & 674 & 7599 & 160395 & 40,2 & 784 & 8150 & 89919 \\
\hline ajo & - & - & 779 & 7173 & - & - & 789 & 7316 \\
\hline albahaca & 0,4 & 28 & - & - & 1,7 & 35 & - & - \\
\hline apio & 13,9 & 874 & 238 & 9227 & s.d. & s.d. & 223 & 8126 \\
\hline berenjena & 61,6 & 3416 & 415 & 13698 & 70,7 & 3846 & 368 & 12023 \\
\hline calabacín & 133,2 & 4129 & 772 & 23532 & 105,2 & 3424 & 728 & 21803 \\
\hline cebollas & - & - & 1347 & 44705 & - & - & 1043 & 43870 \\
\hline coles & s.d. & s.d. & 2046 & 79670 & s.d. & s.d. & 1648 & 64610 \\
\hline endivias & 66,5 & 1522 & 531 & 117715 & 69,3 & 1538 & 556 & 11445 \\
\hline espárrago & 21,2 & 298 & 1315 & 5855 & 31,8 & 370 & 1353 & 5839 \\
\hline fresa & 1142,7 & 22784 & 261 & 4035 & 986,2 & 15952 & 291 & 3776 \\
\hline guisantes & 3,5 & 45 & 649 & 6796 & 4,5 & 55 & 675 & 68999 \\
\hline hinojo & - & - & 254 & 7617 & - & - & 254 & 7094 \\
\hline judías & 52,9 & 1296 & 2500 & 20988 & 41,8 & 982 & 1796 & 13771 \\
\hline lechuga & 196,4 & 4544 & 785 & 18950 & 193,1 & 4265 & 916 & 19351 \\
\hline melón & 567,9 & 11465 & 1021 & 29753 & 608,4 & 12399 & 1069 & 33320 \\
\hline patatas & - & - & 3777 & 136336 & - & - & 4027 & 153039 \\
\hline pepino & 64,5 & 2930 & 500 & 12684 & 62,5 & 2299 & 445 & 9556 \\
\hline pimientos & 108,9 & 3869 & 719 & 21373 & 136,4 & 5521 & 656 & 19775 \\
\hline tomates & 581,4 & 35884 & 1973 & 112050 & 596,8 & 36590 & 1935 & 101850 \\
\hline zanahorias & 3,7 & 205 & 706 & 30990 & 4,7 & 267 & 748 & 29486 \\
\hline otros* & 31,5 & 1868 & 1761 & 55626 & $11,9^{\mathrm{a}}$ & 605 & 1735 & 48808 \\
\hline Total & 3081,1 & 95831 & 29948 & 758773 & 2964,8 & 88113 & 29405 & 773776 \\
\hline
\end{tabular}

* en el epígrafe otros se incluyen cultivos como acelgas, espinacas, nabos, perejil, puerros, rábanos, remolacha, sandía y valeriana ; ${ }^{a}$ la totalidad de la superficie y la producción corresponden a acelgas, sandías y remolachas pues el resto de los cultivos aparecen en la estadística consultada sin desagregar. Fuente: ISTAT. Elaboración propia.

La tendencia contraria se observa en las fresas, tal y como pondremos de manifiesto en el epígrafe dedicado a este cultivo. Mención especial merece la achicoria, pues, aunque su tendencia es alcista, ha experimentado una notable regresión en el municipio de Lusia, como consecuencia del cultivo de variedades poco apreciadas en el mercado y las dificultades que entraña su sustitución ya que entran en competencia con el área productora de Chioggia-Sottomarina, con la que no pueden competir en costes gracias a la «benignidad» de su invierno: son necesarios los acolchados térmicos en la primera frente a los meros túneles en la segunda. Siendo esta hortaliza sustituida por diversas variedades de lechugas (iceberg, capuccia, romana) que se han convertido el cultivo dominante, y asociado a este, zanahorias, pimientos, coles y cebollas. 
SUPERFICIE Y PRODUCCIÓN DE ACHICORIA (1997)

\begin{tabular}{|l|c|r|r|r|}
\hline \multirow{2}{*}{} & \multicolumn{2}{|c|}{ SAU } & \multicolumn{2}{c|}{ PRODUCCIÓN } \\
\cline { 2 - 5 } & sup (ha) & $\%$ & toneladas & $\%$ \\
\hline Venecia & 2.500 & 35 & 35.600 & 34 \\
Verona & 1.800 & 19 & 24.900 & 24 \\
Padua & 1.600 & 18 & 17.600 & 17 \\
Rovigo & 1.300 & 17 & 19.800 & 18 \\
Treviso & 700 & 2 & 4.900 & 4 \\
Vicenza & 300 & 9 & 2.800 & 3 \\
Belluno & - & - & - & - \\
\hline
\end{tabular}

Fuente: Ente Sviluppo Agrario del Veneto. Elaboración propia.

\subsubsection{Achicoria}

Es un cultivo típicamente italiano, aunque desde finales de los años ochenta se ha difundido en Sudamérica (Argentina y Chile) y Norteamérica (estado de California). Analizando la superficie cultivada a nivel nacional en la década de los 90 destaca de manera notable la región del Véneto que concentra el $40 \%$ de la producción. Siendo las provincias vénetas que mayor terrazgo dedican a este aprovechamiento Venecia, Verona, Padua y Rovigo (cuadro 4). La provincia de Treviso, aunque no dedica a este cultivo más de un 5\% de su superficie hortícola, se ha especializado en las producciones más preciadas por el consumidor; habiendo adoptado, asimismo, una serie de políticas de valorización de este producto con la obtención de una denominación de origen para las variedades precoz y tardía del rosso de Treviso y varegiato de Castelfranco y la creación de un consorcio para su promoción, abanderado por la cooperativa OAMT S. Bovo.

\subsubsection{Fresas}

La fresa es un cultivo de honda tradición en el Véneto: las primeras referencias aparecen a principios del siglo XIX aunque asociadas a otros aprovechamientos. No será, sin embargo, hasta la segunda década de la actual centuria cuando aparezcan áreas especializadas que se ubican en la alta llanura veronesa (municipios de Boscochiesanuova, Velo y Campofontana), para posteriormente difundirse en zonas próximas a la ciudad de Verona tanto al norte (Borgo Trento) como al sur (Adigetto) y, en la baja llanura donde adquirirá rasgo de monocultivo a mediados de los setenta: en 1976, el Véneto ocupaba el segundo lugar en la producción de fresas a nivel nacional, recolectándose en Verona 19.500 toneladas, el $70 \%$ de la cosecha regional y ascendiendo la superficie cultivada a unas 1.200 hectáreas ${ }^{19}$.

Terrazgos que han experimentado una progresiva reducción a partir de 1993-94, tras unos años de notable estabilidad como fueron los años ochenta y los primeros noventa. En

19 SALGARO, S. (1976): Un aspetto della dinamica agricola veronese: la fragolicultura, Istituto di Geografia, XIII,15, Università degli Studi di Padova, 32 pp. 
1996-97 éste ha totalizado 817 hectáreas (el $80 \%$ bajo plástico). Concentrándose su cultivo en la provincia Verona ${ }^{20}$ y una pequeña superficie en la de Rovigo (164 hectáreas en el denominado Alto Polesine ${ }^{21}$ ). Las razones de esta disminución son múltiples: la competencia ejercida por la producción española, la pulverización varietal del agro veronés ${ }^{22}$ frente a la variedad única del litoral onubense (camarrosa), la revalorización de la lira en un $15 \%$ en el último bienio, la crisis económica que ha afectado a Italia y Alemania, con la consiguiente disminución del consumo, los costes crecientes que supone la mano de obra ${ }^{23}$ y las adversas condiciones climatológicas que se han producido en las últimas campañas.

La recesión descrita ha sido paralela a la difusión de nuevos aprovechamientos (tomates y calabacines, principalmente) que requieren menos inversiones en mana de obra. Paradigmática ha sido la reconversión de usos en la explotación Giorgio Strambini (municipio de Zevio) que de ser el mayor productor de fresas de la provincia de Verona a mediados de los años ochenta ha pasado a no cultivar ni una plántula en 1998.

Cultivo que, a diferencia del resto de las áreas productoras, se caracteriza por adoptar la denominada técnica «otoñal» en un elevado porcentaje de las explotaciones (85-90\%) que permite la obtención de una doble cosecha (primavera y otoño). Esta última si bien es más reducida (2.000 frente a 10.000 toneladas) posee una notable importancia desde el punto de vista comercial y productivo, pues se ha desarrollado bajo la técnica del cultivo sin suelo. Técnica que en la actualidad está en proceso de abandono debido a una serie de costes adicionales que implica su utilización entre los que destacan el empleo de plántulas de calidad superior $\left(\mathrm{A}^{+} \mathrm{o} \mathrm{WB}\right)^{24}$ o la utilización de productos desinfectantes más vigorosos.

\subsection{Las técnicas de cultivo}

Los cultivos hortícolas vénetos presentan, desde el punto de vista de las técnicas de cultivo, una dualidad entre aquéllos que se realizan al aire libre y los que se llevan a cabo bajo plástico. Sin embargo, estas superficies (cuadro 3) tienen un carácter más informativo que real debido a una serie de aspectos que deben ser considerados entre los que destacan

20 La importancia de este cultivo en Verona queda reflejado en las siguientes cifras, unos dos millones de jornales y unos ingresos en torno a los 28,822 millones de euros.

21 Superficie que ha experimentado un incremento significativo desde los años 70 cuando se cultivaban unas 20 hectáreas.

22 Las variedades más difundidas en el agro veronés son la marmolada y tudla con unos porcentajes que se sitúan en torno a un 70 y un $15 \%$, respectivamente. El tanto por ciento restante se completa con variedades como la tethis, la miss, elsanta y chander.

23 La mano de obra durante el periodo de recolección es un inconveniente dada la dificultad de encontrar trabajadores para el periodo de la recolección, pues se ha calculado que se requieren 7 personas/ha/día. Éstos proceden en un $30 \%$ de mano de obra familiar y el resto de asalariados, generalmente meridionales (Basilicata, Campania, Abruzzo y Cerdeña) o extracomunitarios. Traba que se ha intensificado en las últimas campañas como consecuencia de una serie de normativas legales aprobadas a finales de los años ochenta y que obligaban a contratar a empleados eventuales que estuvieran inscritos en las listas de desempleo. Imposición que determinó la aparición del trabajo negro y la contratación de personas poco motivadas. El empleo de trabajadores extracomunitarios tampoco ha solucionado el problema, ya que una vez obtenido el permiso de residencia, optan por actividades más rentables; asimismo su utilización ha generado serias controversias durante las campañas de 1996 y 1997. Para la primera se firmó un acuerdo que estipulaba la contratación de 800 emigrantes durante 18 días, sin embargo, la lentitud burocrática determinó que los permisos llegasen una vez concluida la época de la recolección. Demora que trató de paliarse en 1997 al ratificarse estos contratos cinco meses antes de su inicio. Actuación que recibió numerosas críticas desde amplios sectores acusándola de favorecer la llegada de emigrantes de manera encubierta.

24 Los precios medios de la campaña de 1998 se han situado en $0,10 / 0,12$ euros para la planta tipo A (8-10 $\mathrm{mm}), 0,18$ para la $\mathrm{A}+, 0,20-0,25$ euros para la WB y $0,07 / 0,10$ para las plántulas con un grosor inferior a los 8 milímetros y utilizadas para la cosecha única. 
la alternancia de ambas técnicas por un elevado porcentaje de explotaciones agrícolas y la notable expansión que los aprovechamientos bajo plástico han registrado en los últimos años, como confirma la comparación de los mapas de usos del suelo del litoral veneciano elaborado mediante la restitución fotogramétrica de los vuelos de 1990 y 1996 y que no se refleja en el cuadro número 3 donde esta superficie incluso ha disminuido (lámina 3).

Su adopción ha permitido, por un lado, adelantar la cosecha y, por otro, intensificar la producción, obteniéndose 3 cosechas en algunas variedades de lechugas (capuccia, iceberg, romana) y 4 en las achicorias (variedades Chiogga o en la de Treviso: precocissimo, precoz, medio y tardío) al cultivarse la tierra de manera continua durante 9-10 meses. Estableciéndose un periodo de descanso en diciembre y enero como consecuencia de las bajas temperaturas, que frecuentemente descienden bajo cero incluso durante todo el día, que impiden el crecimiento de las hortalizas a no ser que se lleven a cabo en invernaderos con calefacción. Variedades que, no obstante, presentan diferencias en las técnicas de cultivo según la época del año en que se planten. Así, las dos primeras debido a las bajas temperaturas (enero-febrero), son sembradas en invernaderos, generalmente, con calefacción. Trasplantándose, posteriormente a terrazgos con sistemas de protección como pueden ser pequeños túneles o los acolchados (marzo y abril). Técnicas que dejan de emplearse en las variedades «media» y «tardía» en las que las temperaturas permiten su cultivo al aire libre. Siendo irrelevantes las explotaciones que realizan todo el ciclo productivo en invernadero con calefacción, salvo en el caso de las flore ${ }^{25}$, dados los elevados costes que implica su construcción y mantenimiento.

No obstante, esta superficie se ha incrementado gracias a la progresiva sustitución de los cultivos hortícolas por los de flor cortada, buscando una mayor rentabilidad dadas las reducidas superficies que presentan (el $80 \%$ tiene una superficie en torno a los $1.000 \mathrm{~m}^{2}$ ). La excepción estos rasgos la encontramos en la iniciativa llevada a cabo por el ENEL, que ha construido, con fondos europeos, 7 hectáreas de invernaderos de cristal y que utilizará las aguas de refrigeración de la central termoeléctrica Camerini para la calefacción. Iniciativa inaugurada el 5-4-1998.

Técnicas que, a pesar de su reciente adopción, han experimentado ciertas innovaciones especialmente en aquellas áreas en las que su empleo es más antiguo, como, por ejemplo, la baja llanura de Verona. Entre éstas merecen citarse el incremento de las dimensiones de los túneles ${ }^{26}$ para facilitar la maniobrabilidad de la maquinaria, lo que conlleva la utilización de materiales cada vez más resistentes al viento y, consiguientemente, un aumento de los $\operatorname{costes}^{27}$, la adopción de nuevos métodos como son los hidropónicos que se iniciaron a principios de la década de los 90 y la reciente difusión de la lucha integrada.

El cultivo sin suelo ha experimentando un notable crecimiento desde 1995 gracias a la reducción de sus costes tras la aparición en el mercado de empresas italianas dedicadas a la fabricación de bolsas de perlita y lana de roca ${ }^{28}$. Ocupando éste a finales de 1997 unas 38

25 El cultivo de flor cortada ha experimentado una progresiva expansión desde mediados de la década de los ochenta, en un primera etapa, como complemento de rentas y desde la década de los noventa como aprovechamiento único, gracias a la elevada rentabilidad obtenida, por ejemplo, la unidad de geranio se ha pagado a 1,80 euros (1998). Invernaderos que realizan 3 ciclos de cultivo: el primero de enero y abril (geranios), el segundo de mayo a septiembre (claveles) y el tercero de octubre a diciembre (crisantemo y flor de navidad).

26 La altura puede así alcanzar hasta los 2,5-3 metros. Permanece invariable la amplitud (alrededor de 4,5$5 \mathrm{~m}$ ) mientras que se ha reducido la longitud (40-60 m.) para permitir una mejor gestión del microclima interno y favorecer la atomización con los tratamientos antiparasitarios

27 El coste de $1 \mathrm{~m}^{2}$ de túnel se sitúa en torno a los 7,74 euros, ascendiendo a 20,65-23,24 euros si éstos presentan estructura de invernadero. 
hectáreas y siendo practicada en 56 explotaciones frente a las 450 hectáreas del resto de Italia. Incremento que ha sido paralelo a la reducción del cultivo al aire libre que ha pasado de ocupar un 30\% de la superficie en 1994 a un 5\% en 1998. Difusión de los cultivos protegidos que ha ido unido a la proliferación de las técnicas de riego localizado bien manual o automatizado ${ }^{29}$. Técnica (cultivos hidropónicos en invernadero) que, se ha difundido, asimismo, durante las tres últimas campañas en el litoral norte veneciano, asociado al cultivo de tomate donde para reducir costes incluso se ha introducido los circuitos de la calefacción caudales subterráneos (aguas termales).

La lucha integrada, aunque en fase experimental, comienza a adaptarse en algunas explotaciones $^{30}$ a pesar de los «inconvenientes» evidenciados tanto por los técnicos del Consorzio Verde Europa como por los propios agricultores. Impedimentos que podemos resumir en la necesidad de adoptar una nueva organización de la explotación y los elevados costes iniciales. La investigación sobre diversos medios químico-físicos (solarización ${ }^{31}$, tratamiento con microondas, vapor, etc.), biológicos o agronómicos (prolongación de la duración de las rotaciones, adecuada preparación del terreno, etc.) para la desinfección de los terrazgos se vincula a la inclusión del bromuro de metilo (el producto más utilizado) en el protocolo de Montreal como una de las sustancias que contribuye al agujero de ozono. Inserción que conlleva una reducción progresiva de su uso hasta su total prohibición en el 2006. Disminución que se ha plasmado en un incremento notable (un 40\%) de los precios del producto si comparamos los de 1997 y 1998.

\subsection{Comercialización}

La comercialización de los productos hortícolas vénetos se realiza a través de 3 canales, a saber: estructuras asociativas, a través de un intermediario (40\%) y la venta directa ( $40 \%$ de la producción). Los porcentajes citados evidencian la escasa difusión de cooperativas y de las asociaciones de productores. Presentando, además, otros rasgos negativos como su concentración en ciertas producciones como el tomate para la industria $a^{32}$, la achicoria ${ }^{33}$ y la fresa o sus reducidas dimensiones tanto por el número de $\operatorname{socios}^{34} \operatorname{como}$ por la producción

28 La aparición en los primeros años noventa de empresas italianas ha reducido el coste de una bolsa de perlita en una quinta parte. En 1998 el precio de la bolsa 30 x 40 (10 litros, apta para 6 plántulas) asciende a unos 0,87 euros y a 1,29 si las dimensiones son 30 x 60 .

29 La instalación de un sistema de irrigación controlada por un ordenador central asciende a 2.582,28 euros/ $1.000 \mathrm{~m}^{2}$.

30 A finales de 1997 ésta ocupaba una superficie en torno a las 10 hectáreas, de las 400 que los socios de la cooperativa Verde Italia dedicaban al cultivo de la fresa.

31 Técnica que fue introducida de modo experimental por el propio Ente di Sviluppo Agrario del Veneto (ESAV). Consiste en regar abundantemente la tierra durante el mes de julio (el más cálido) y cubrir la superficie con un plástico de nylon lo que determina un ascenso de la temperatura hasta los 40-45 grados, produciéndose una reducción alrededor de un $80 \%$ de las esporas en los 10-15 primeros centímetros.

32 En Bibione se produce una nítida diferencia entre los agricultores que se han monoespecializado en el cultivo del tomate y los que cultivan hortalizas en general. Los primeros comercializan a través de la cooperativa agrícola local, constituyendo éste alrededor del 50\% de la mercancía total gestionada, frente a los segundos en los que se observa una mayor heterogeneidad, pues alternan aquéllos que acceden al mercado a través de la cooperativa y los que lo hacen directamente, generalmente, con la instalación de un punto de venta en su propia casa, siendo sus principales compradores los turistas.

33 Aunque la achicoria es uno de los cultivos donde el asociacionismo es más relevante, en la campaña de 1998, estos organismos únicamente comercializaron 30.000 toneladas de las 98.000 producidas.

34 El número de cooperativistas es generalmente inferior a los 200, salvo la Centrale Orticola de Bassano, una de las más potentes del Véneto, con 400 socios. 


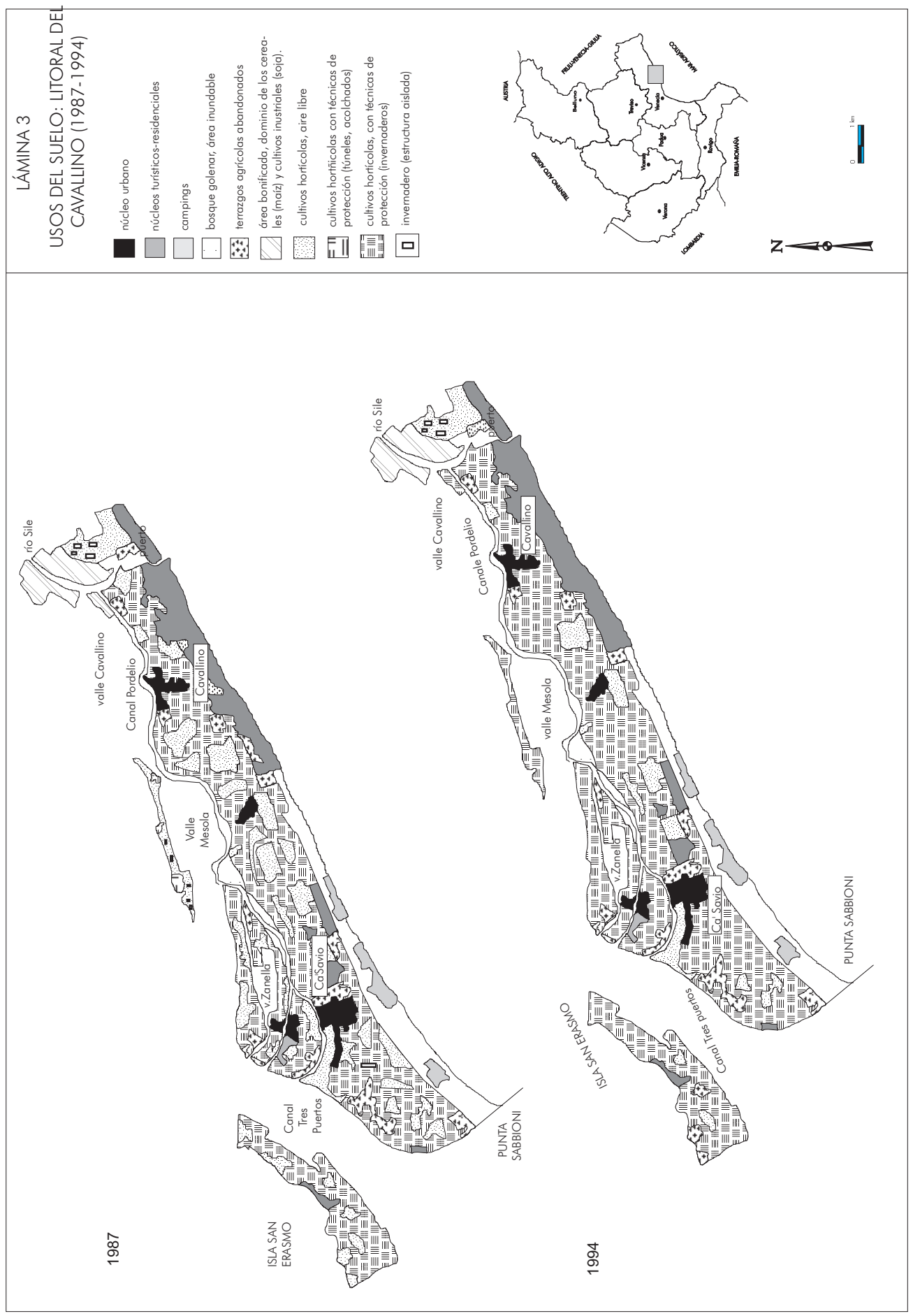


comercializada ya que un elevado porcentaje distribuye menos de 5.000 toneladas al año, siendo su mercado potencial el local: los clientes de la cooperativa de Lusia se sitúan en un radio de actuación que no supera los $50 \mathrm{~km}$.

Formas asociativas que, generalmente, no tienen más función que la de actuar como centros de recolección sin activar políticas de planificación de los cultivos, de asistencia técnica o de sistemas de comercialización o de elaboración de productos. La carencia de estos procesos la justifican sus directivos e integrantes por los elevados costes que supone; aunque éstos fácilmente serían compesados si atendemos a la diferencia de precios percibidos por los productores de lechugas en Lusia, una vez descontado el precio del embalaje, que ha duplicado al obtenido por los socios de la cooperativa de Rosolina, donde el producto se vende sin confeccionar ${ }^{35}$.

Esta debilidad implica, asimismo, que parte de los ingresos generados por el sector agrícola quedan fuera del círculo de los productores. Así, por ejemplo, en la campaña $1997 / 98$ el kilo de achicoria se ha pagado a los agricultores a 0,30/0,36 euros/ $\mathrm{kg}$ mientras que en los mercados se ha situado en torno a los 1,54 euros. Excepción a estos rasgos se observa en la $A P O$ Veneto-Friuli que comercializa a través de la cooperativa de OAMT S. Bovo, la cooperativa de Lusia que posee un stand propio en una lonja y ha iniciado técnicas de manipulación o el Consorzio Verde Europa (cooperativa de segundo grado, Verona), que comercializa con marca propia (Gli Orti di Giulietta).

\subsection{Distribución espacial}

Los rasgos descritos en epígrafes anteriores adquieren una gran relevancia desde el punto de vista espacial. Aprovechamientos que no se presentan de manera difusa por el territorio sino que se constituyen a modo de «islas» en un paisaje extensivo, característico de áreas bonificadas. Estudio pormenorizado por la elevada superficie ocupada por las técnicas bajo plástico merecen el litoral veneciano, la baja llanura de la provincia de Verona y el Bajo Polesine (lámina 2).

\subsubsection{El litoral veneciano}

El litoral veneciano, al igual que ha sucedido en gran parte de la costa valenciana, ha experimentado notables mutaciones en los usos del suelo desde 1960. Pudiendo sintetizar estas transformaciones en la aparición de nuevos aprovechamientos entre los que destacan los turístico-residenciales que, en ciertos espacios, van a sustraer áreas de elevado potencial agrícola ${ }^{36}$ y la difusión de los cultivos bajo plástico frente al abandono de terrazgos cultivados al aire libre. Usos, que presentan una ocupación selectiva del territorio: aquéllos se desarrollan en primera línea de costa frente a los segundos que quedan retranquedos hacia el interior tal y como se observa en el municipio de Jesolo y en las partidas de Punta Sabbioni y Cavallino ${ }^{37}$ (municipio de Venecia, lámina 3) y en la de Sottomarina (municipio de Chioggia, lámina 4). Sectores citados donde los aprovechamientos hortícolas son rele-

35 El precio percibido por los asociados de Lusia ha ascendido a 0,88 euros $/ \mathrm{kg}$ frente a los 0,30 de Rosolina.

36 A modo de ejemplo podemos citar el municipio de Chioggia donde a finales de 1997 se cultivaban unas 359 hectáreas frente a las 565 de 1961. Disminución que ha venido acompañada, asimismo, de un descenso en el número de activos: en 1997 la practican unos 850 agricultores a tiempo completo, frente a los 2.500 y 1.500 existentes en 1951 y 1971 (Ginestri, M. 1975).

37 La carretera establece un límite claro entre ambos usos: las segundas residencias, hoteles y campings se han desarrollado sobre el antiguo cordón dunar que se conserva en la partida de Punta Sabbioni mientras que los hortícolas quedan delimitados por la laguna y la carretera provincial número 42 . 


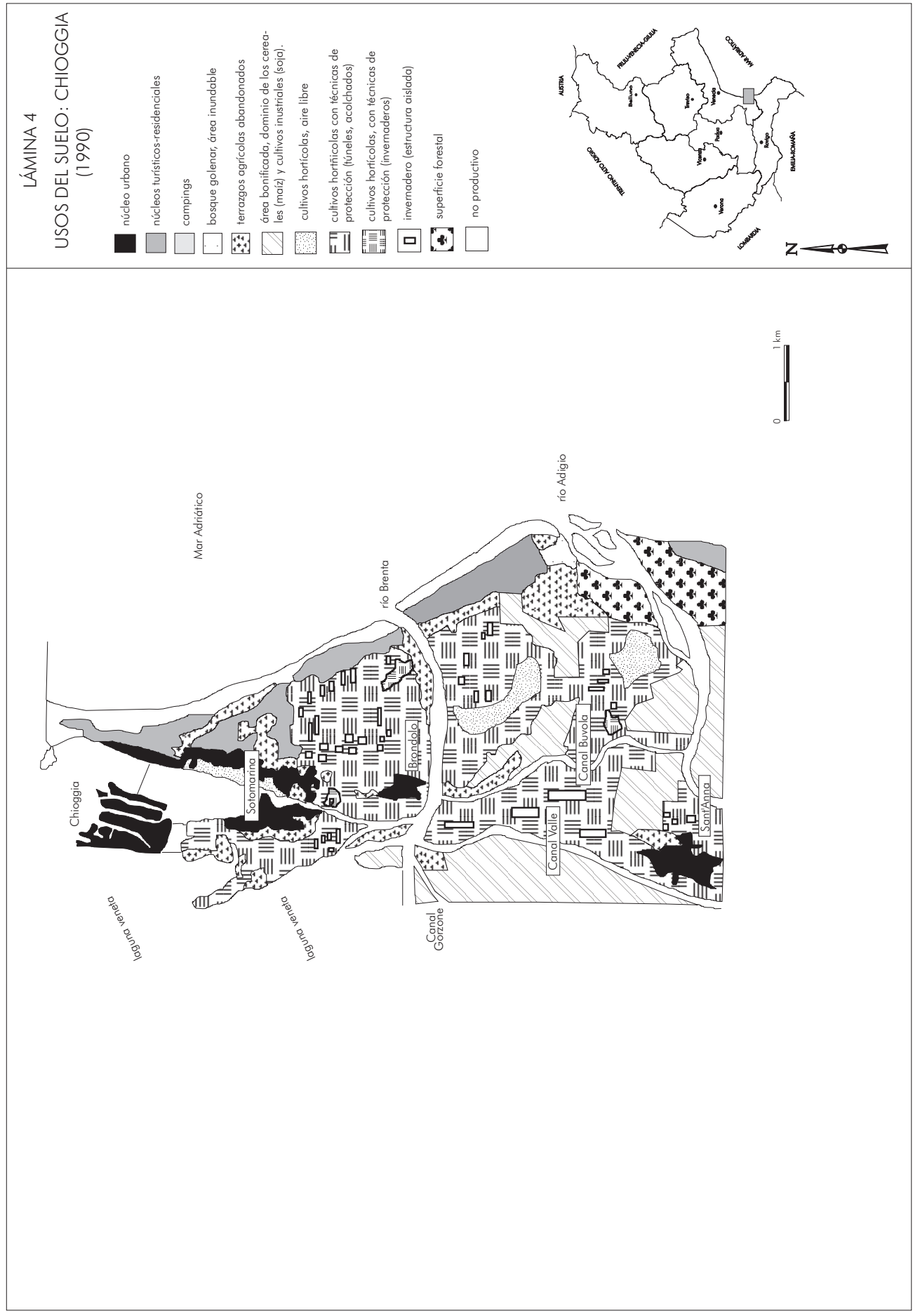



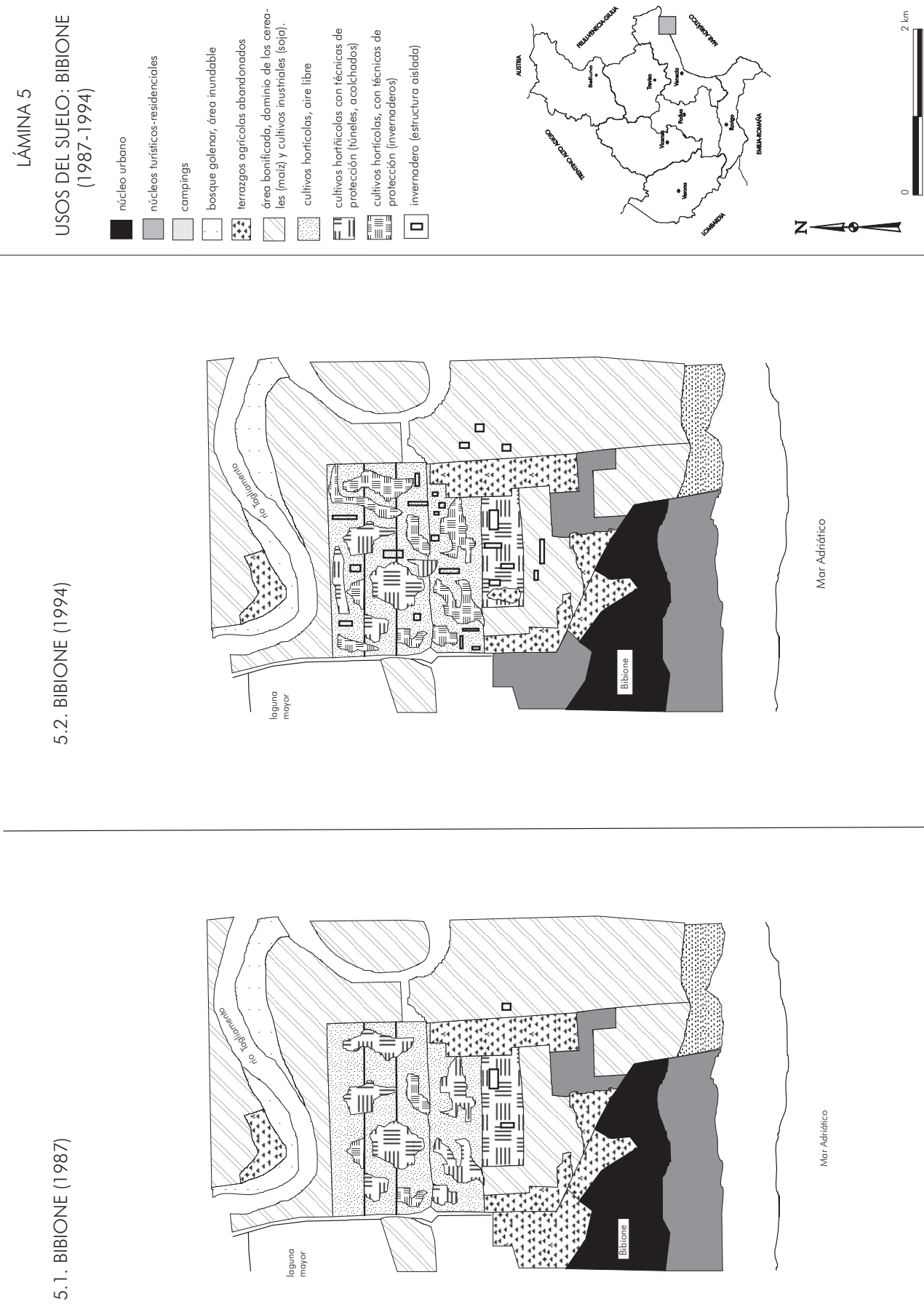
vantes a diferencias de otros espacios litorales como Bibione donde las actividades turísticas adquieren rango de monocultivo, presentando las hortalizas una localización puntual ${ }^{38}$ (lámina 5).

Sector donde podemos establecer varias subáreas si analizamos los aprovechamientos y las técnicas empleadas: al norte de Venecia predomina el tomate que ocupa alrededor del $80 \%$ del terrazgo cultivado, siendo el resto dedicado a berenjenas y pimientos, frente al litoral sur donde la achicoria (variedad de Chioggia) ha adquirido el rango de monocultivo. Cultivos que, en el primero de los espacios, se desarrollan en invernaderos frente al dominio de los pequeños túneles en Sottomarina-Sant'Anna (lámina 2). Ocupando estos sistemas de protección una superficie que oscila entre el $90 \%$ en el litoral de Jesolo, un $60 \%$ en Chioggia y un 35-40\% en Bibione. Sin embargo, en las dos últimas áreas citadas estas prácticas se levantan a finales de abril, con lo que la cuantificación de la superficie protegida es más compleja. No siendo arriesgado situarla en torno al 50\% en Bibione y un $80 \%$ en Chioggia, tal y como confirma el trabajo de campo.

Aprovechamientos que en lido de Sottomarina se remontan en el tiempo tal y como confirma la documentación escrita y, sobre todo, la cartografía de los siglos XVI y XVII ${ }^{39}$. Terrazgos que, no obstante, van registrar notables transformaciones desde mediados de los años sesenta y que podemos resumir en la sustitución del policultivo hortícola por un monocultivo (achicoria variedad de Chioggia), una cierta racionalización de las explotaciones que se manifiesta en un incremento de las dimensiones de las explotaciones y en la reordenación de los parcelarios (supresión de numerosos canales de drenaje) para permitir la maniobrabilidad de la moderna maquinaria, la difusión de técnicas de protección y el «traslado» de las explotaciones a otros municipios ${ }^{40}$. Modernización que ha irradiado a los sistemas de comercialización: el mercado de Sottomarina, situado en el centro de la ciudad se trasladó a Brondolo (sector sur del término municipal) a unas nuevas instalaciones lo que ha favorecido la concentración de la producción y su comercialización e, indirectamente, la difusión de este aprovechamiento a otras pedanías como, por ejemplo, Sant'Anna, compensando, de este modo, la pérdida de terrazgos en el área litoral.

\subsubsection{El Basso Polesine (provincia de Rovigo)}

El sector meridional de la provincia de Rovigo, el denominado basso Polesine, ha sido considerado tradicionalmente como «il meridione interno», viéndose afectado por la Ley de Reforma Agraria (Legge Stralcio della Riforma Fondiaria) en los años 50. Subdesarrollo que en ocasiones ha sido relacionado con el retraso de la agricultura que, a diferencia de

38 Los cultivos hortícolas en Bibione ocupan una superficie de 250-300 hectáreas; estando limitados por el cauce más externo del río Tagliamento y la carretera provincial número 74 San Michele al Tagliamento. Paisaje intensivo cuyo origen se remonta a finales de la Segunda Guerra Mundial cuando la población italiana de la península de Istria fue expulsada tras pasar ésta a formar parte de la ex-Yugoslavia. Población que fue asentada en el área que actualmente se conoce en el municipio con el expresivo nombre «orti». Correspondencia que no es casual sino que fueron estos «istrianos» quienes llevaron a cabo esta transformación del paisaje ya que dada la reducida superficie donde debían instalarse el único modo de poder sobrevivir era obtener varias cosechas en una misma parcela. Terrazgos que desde mediados de los años ochenta han experimentado una nueva mutación como es la difusión de las técnicas bajo plástico, bien mediante pequeños túneles o estructuras de invernadero con o sin calefacción.

39 ROTONDI, G. y ZUNICA, M (1995): Il lido di Sottomarina. Processi Interattivi di costruzione e consumo, Dipartimento di Geografia, Università degli Studi di Padova, Padua.

40 Algunos agricultores ante la imposibilidad de aumentar la superficie de sus explotaciones y dada la proximidad a la línea de costa procedieron a vender sus tierras y a comprar en municipios limítrofes como Rosolina, en una primera fase, y posteriormente en las provincias de Ferrara y Rávena. 

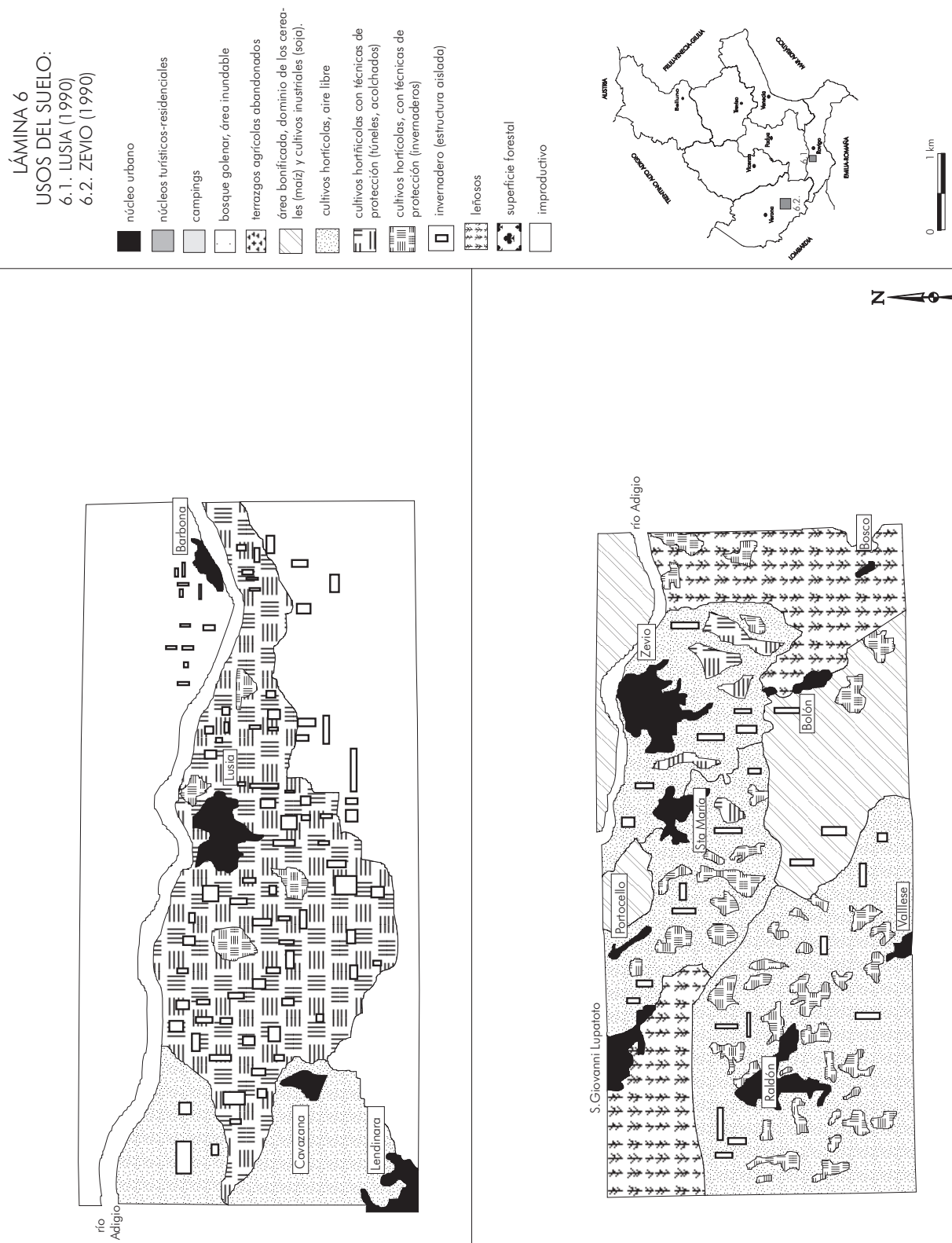

$\frac{\varangle}{5}$
$\Xi$
- 
otras provincias, no ha favorecido la difusión de otras actividades. Área marginal que comenzó a ser puesta en valor por la República de la Serenísima ${ }^{41}$ dando lugar a un característico paisaje de bonificación. Aprovechamientos herbáceos que a partir de finales de los años setenta han experimentado ciertas modificaciones, aunque puntuales, que podemos sintetizar en la intensificación de los usos (difusión de los frutales y los cultivos hortícolas, en el Medio y Bajo Polesine, respectivamente). Estos últimos han visto incrementada su superficie de manera significativa pues de 602 hectáreas en 1951 (Manfredini, G.; 1979) han pasado a unas 5.470, según los datos proporcionados por la Cámara de Comercio de Rovigo.

El municipio de Lusia es un ejemplo paradigmático en el Bajo Polesine (lámina 6). Fue pionero en la sustitución de los aprovechamientos; transformaciones iniciadas en la década de los setenta por iniciativa de los propios agricultores lo que justifica que en 1997, éstas se circunscriban a su término municipal y, por ejemplo, en Barbona, que se ubica al otro lado del Adigio, la presencia de cultivos bajo plástico sea meramente testimonial. Mutaciones que se vincularon a la introducción de nuevos aprovechamientos, la intensificación de las técnicas adoptadas y la mejora de los canales de comercialización. Ésta, una de las carencias del Polesine, se resolvió con la creación de una Centrale ortofrutticola, perteneciente a la Cámara de Comercio de Rovigo. Modificaciones que le han proporcionado una gran vitalidad económica. Aspecto que se observa en su conversión en un área receptora de población frente a su tradicional carácter emisor y, sobre todo, en los niveles de vida de sus habitantes, que han transformado las antiguas casas en garajes para la maquinaria agrícola y junto a ellas se han construido una nueva vivienda o en el número de bancos existentes en el municipio: tres para una población de 2.000 habitantes.

\subsubsection{La baja llanura de la provincia de Verona}

Esta área ha experimentado, como consecuencia de la crisis que afecta al cultivo de la fresa, una progresiva reducción de su superficie y una paulatina sustitución por otros aprovechamientos hortícolas. Transformaciones que han irradiado a la estructura de las explotaciones: a finales de los años 60 predominaban las unidades productivas mediograndes (más de 10 hectáreas) mientras que en 1998, el 80\% de la superficie dedicada a la fresa se realiza en explotaciones de pequeñas dimensiones (1-2 hectáreas $)^{42}$.

Ejemplo característico de un municipio donde se practica el monocultivo de la fresa es Zevio (lámina 7) ya que el $80 \%$ de su superficie útil se dedica a éste y donde se requieren más de 1.000.000 de jornales para su recolección. Concejo cuyos productores en un elevado porcentaje, junto con los de Cerea y Bovolone, se han integrado en el Consorzio Verde Europa ${ }^{43}$, cuyo número de socios, en su mayoría agricultores con dedicación exclusiva, asciende a 350 de los que 150 se dedican mayoritariamente al cultivo de la fresa, concentrando unas 406 hectáreas y el 70\% de la producción véneta. Cultivo que en sus $2 / 3$ partes se dedica a la exportación. Siendo los principales mercados Alemania y Austria (5.211,7 y 1.443,8, respectivamente sobre un total de 7.796,8 toneladas). Exportación

41 CROCE, D. (1984): «Paesaggio e strutture agrarie», en ZUNICA, M. (cord.) Il delta del Po. Terra e gente aldilà dei monti di sabbia, Rusconi, Milán, pp. 185-225.

42 La explotación modelo sería aquella que dedica 1,5 hectáreas a la explotación de fresas y 0,5 a trabajos de preparación del terreno tal y como han confirmado las entrevistas realizadas en Grosseto y Santa María, pedanías de Bovolone y Zevio, respectivamente. Explotaciones que compatibilizan este cultivo con los aprovechamientos hortícolas y los leñosos (frutales: manzanos, perales y kiwi).

43 El Consorzio, cooperativa de segundo grado, nació hace año y medio, de la fusión de dos cooperativas que se convirtieron en Asociaciones de Productores. 
favorecida por la proximidad de los mercados tras la apertura de la autopista del Brennero, así como por el hecho de que el producto llega al mercado cuando la producción meridional está prácticamente agotada.

\section{Conclusiones}

La necesidad de obtener rentas más elevadas para poder competir con otros usos como pueden ser las actividades turístico-residenciales en el área litoral, las industriales en sectores colinares y de la llanura padana o la inexistencia de otras actividades con el consiguiente predominio de una agricultura extensiva se ha traducido en la difusión de la horticultura bajo plástico, bien mediante invernaderos u otras formas de protección. Intensificación que se ha producido generalmente en estructuras familiares, la dominante en esta región, lo que permite satisfacer directamente la mano de obra necesaria, salvo excepciones como en el caso de la fresa y generar positivas consecuencias desde el punto de vista social, ya que asegura el mantenimiento de esta actividad gracias a las rentas obtenidas que se cifran de media en unos 9.812,68 euros por hectárea, unas 4 veces superior a las explotaciones cerealícolas, las dominantes en la región, gracias a la antelación de la cosecha, lo que permite obtener precios elevados ${ }^{44}$ dada la escasez del producto al inicio del periodo de recolección y en la reducción del ciclo de cultivo (de 90 a 70 días). Contenido social incrementado, asimismo, por el hecho de la elevada profesionalidad de los practicantes, con frecuencia jóvenes frente al creciente envejecimiento de los titulares de explotaciones tradicionales.

\section{Bibliografía}

A.A.V.V. (1995): «L'orticoltura italiana verso il 2000», en Eurofruit Magazine, marzo 1995.

BEGALLI, D.; BERNI, P. y BOATO, V. (1988): L'industria agro-alimentare veronesa. Strutture e risoltati economico-finaziare, Cámara de Comercio, Industria y Agricultura, Verona.

BERNARDI, R. (1994): «La cooperazione in agricoltura e le trasformazioni strutturali del settore», Boletín de la Sociedad Geográfica Italiana 1, pp. 35-50.

DOLCETTA, B. (cord.) (1984): Il paesaggio veneto, Junta Regional del Véneto, Venecia.

FAEDI, W. (cord.) (1998): La fragola verso il 2000, Convegno Nazionale, Verona 13 febrero 1998, Cámara de Comercio, Industria y Agricultura, Verona.

FILO DELLA TORRE, R. (1997): «OCM ortofrutta: l'UE chiarisce ma l'Italia arranca», L'Informatore Agrario, $\mathrm{n}^{\circ} 31$.

FRANCESCHETTI, G. e TEMPESTA, T. (1993): La pianificazione del territoiro rurale del Veneto negli anni ottanta, Unipress, Venecia.

GINESTRI, M. (1975): «Chioggia tra laguna e terraferma», Giornale Economico della Camera di Commercio, Industria, Artigianato di Venezia, $n^{\circ}$ 5-6, pp. 5-31.

GRILLOTTI DI GIACOMO, M.G. (1989): «Sistema agricolo e sviluppo del territorio in Italia negli ultimi venti anni», en DI BALSSI, A (cord.): L'italia che cambia. Il contributo della Geografia, Atti XXV Congr. Geogr. Ital. vol. III, Catania, pp. 167-188.

INSTITUTO DI STATISTICA ITALIANO (ISTAT): Censimento Generale dell'Agricoltura. Volúmes correspondientes a 1951, 61, 71, 81 y 91 de las provincias de Padua, Rovigo, Venecia, Verona, Vicenza y Treviso.

ISTAT: Le regione in cifre. Volúmenes correspondientes a 1990, 1997, Roma.

44 Los precios de la achicoria han oscilado en la campaña 1997 de 0,11 euros/kg en el periodo de máxima saturación del mercado a los 1,11 euros $/ \mathrm{kg}$ en la primera recolección. 
ISTAT: Censimento della populazione. Volúmenes correspondientes a 1961, 71, 81 y 1991, Roma. MANFREDINI GASPARETTO, M.L. (1979): Il Polesine, economia reale e piano regionale di sviluppo, CEDAM, Padua.

SCARPELLI, L. (1996): Veneto, Geografia dei Sistemi Agricoli Italiani, REDA, Edizioni per l'agricoltura, $170 \mathrm{pp}$.

SETTI, G. (1996): «Dossier radicchio: così cambia la coltura», en Terra e vita, no 36, Florencia, pp. $12-22$. 
21

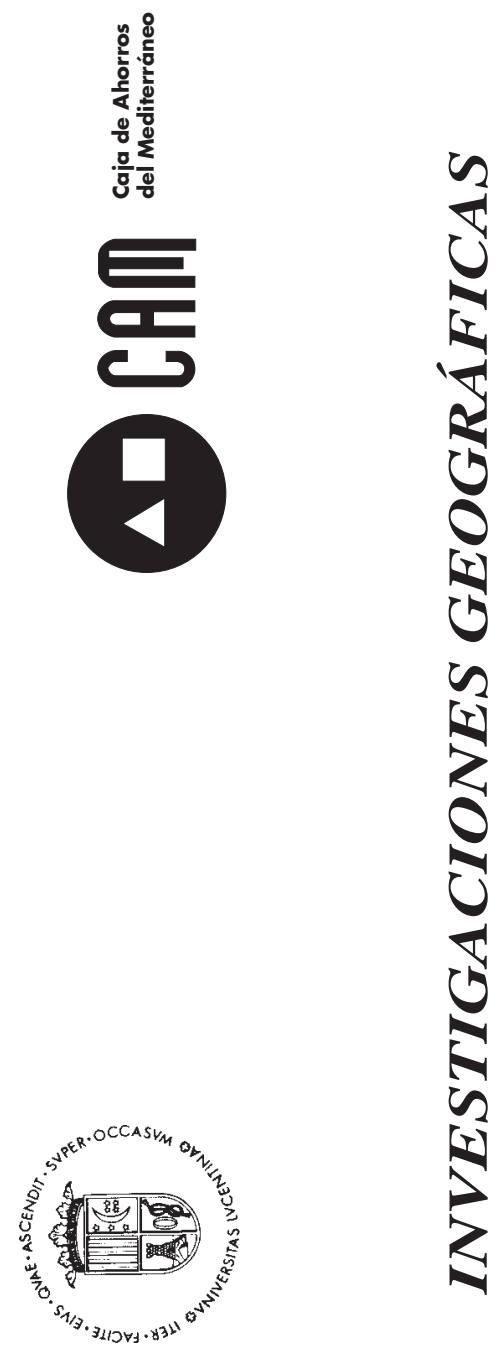

